\title{
Granulomatous Mastitis: A Spectrum of Disease
}

\author{
Ragu Vinayagam ${ }^{a} \quad$ Julie Cox ${ }^{a} \quad$ Lesley Webb ${ }^{b}$ \\ a Department of Radiology, University Hospital of North Durham, \\ ${ }^{\mathrm{b}}$ Breast Screening Unit, University Hospital of North Tees, Stockton, UK
}

Key Words

Granulomatous mastitis · Breast

\section{Summary}

Background: Granulomatous disease within the breast can result from a variety of causes. Patients and Methods: We present 3 cases of this condition with 3 different underlying diagnoses. Results: Each case was initially labelled as idiopathic granulomatous mastitis, although this was proven not to be correct on further investigation. Conclusion: Clearly, identifying the correct underlying diagnosis is essential in granulomatous breast lesions as the treatment varies widely depending on the underlying aetiology. Effective communication and feedback in the context of the multidisciplinary team are vital to the diagnostic process in such challenging cases.

\section{Introduction}

Idiopathic granulomatous mastitis is a rare benign breast disease, first described by Kessler and Wolloch in 1972 [1]. It is characterized by chronic necrotizing granulomatous lobulitis of unknown aetiology. It often mimics breast carcinoma both clinically and radiologically. Wide local excision, with or without corticosteroid therapy, has often been used to treat such patients, with a high recurrence rate.

The term granulomatous mastitis is sometimes used as a default pathological diagnosis when a pathology specimen from the breast shows a chronic granulomatous inflammatory reaction. We present a series of 3 interesting patients from 3 different breast centres. Each presented quite differently, one as a mimic of malignancy, the second as a screen-detected lesion, and the third as a case of breast infection. All 3 cases

\author{
Schlüsselwörter \\ Granulomatöse Mastitis · Brust
}

\section{Zusammenfassung}

Hintergrund: Granulomatöse Erkrankungen der Brust können viele verschiedene Ursachen haben. Patienten und Methoden: Wir berichten von 3 Patientinnen mit granulomatösen Erkrankungen der Brust und jeweils unterschiedlichen zugrunde liegenden Diagnosen. Ergebnisse: Bei allen 3 Fällen war ursprünglich von idiopathischer granulomatöser Mastitis ausgegangen worden. Weitere Untersuchungen zeigten jedoch, dass dies inkorrekt war. Schlussfolgerung: Die korrekte Identifizierung der zugrunde liegenden Erkrankung ist bei granulomatösen Brusterkrankungen von größter Bedeutung, da die Behandlung je nach Ätiologie sehr unterschiedlich ausfällt. Effektive Kommunikation und Feedback innerhalb des multidisziplinären Teams sind ausschlaggebend für den diagnostischen Ablauf bei derart schwierigen Fällen.

initially carried a label of idiopathic granulomatous mastitis, but when analysed more carefully, each case arose from a different aetiology.

\section{Case Reports}

\section{Case 1}

A 58-year-old woman with poorly controlled diabetes mellitus presented to symptomatic breast services with several firm lumps in her left breast. She had had a normal screening mammogram 6 years previously. She had been diagnosed with diabetes mellitus 2 years later and had rapidly developed diabetic complications. Clinical examination revealed several discrete $1.5-\mathrm{cm}$ lumps in the upper half of her left breast with no palpable axillary lymphadenopathy. Bilateral mammography demonstrated multiple 2-cm ill-defined mass lesions in the upper half of the left breast. Ultrasound scan of her left breast demonstrated irregular hyperechoic lesions; imaging was graded as BI-RADS 4 (fig. 1). The overall radiolo-

\section{KARGER}

Fax +497614520714

Information@Karger.de

www.karger.com
(C) 2009 S. Karger GmbH, Freiburg
Dr. Julie Cox

Department of Radiology

University Hospital of North Durham

North Road, Durham, DH1 5TW, UK

Fax +44 1913332948

j_cox@talk21.com 
gical assessment was suggestive of breast malignancy, possibly multifocal in nature. Fine needle aspiration cytology of a lesion demonstrated a benign $\mathrm{C} 2$ result. Because there was significant clinical and radiological concern despite the benign cytology, the largest of the lesions was excised. This showed evidence of granulomatous inflammatory cells with negative stains for acid-fast bacilli and fungi; it was labelled histologically as granulomatous mastitis. The patient presented again 3 years later with new lumps within both breasts and also cutaneous thickening in her right thigh. When excision biopsies were performed on both areas, these showed similar histological appearances of a granulomatous inflammatory reaction. The diagnosis was then labelled as 'lipoidica' secondary to diabetes mellitus. Histologically, the appearances are similar although clinical correlation would differentiate between the two conditions.

Case 2

A 49-year-old woman was recalled for assessment after her screening mammograms showed a dense ovoid lesion in her left breast. She had a 15-year history of both Sjogren's syndrome and fibromyalgia. Bilateral mammography revealed an unusual $2-\mathrm{cm}$ lesion in the lower inner quadrant of her left breast. Ultrasound scan showed the lesion to be hypoechoic without any characteristic benign features; overall the BI-RADS grade was 3 (fig. 2). Fine needle aspiration cytology showed non-caseating granulomatous inflammatory reaction $(\mathrm{C} 2)$. A pathological diagnosis of granulomatous mastitis was given. While the condition is idiopathic, in this case it was most likely to be secondary to the patient's well-documented autoimmune disorders. This is also the first documented screendetected case of granulomatous disease in the breast to our knowledge. The patient required no further specific treatment.

Case 3

A 50-year-old woman with 3 children presented to the symptomatic breast clinic with a 1-year history of episodic right breast tenderness with a lump and clear discharge. She was diagnosed with mammary duct ectasia, and a microdochectomy was performed 1 month later. She subsequently represented several times with recurrent breast abscesses in both breasts. Ten years later, she presented to us with a 5 -cm left subareaolar mass with nipple discharge. Mammography demonstrated an irregular dense left retro-areolar mass. An ultrasound scan showed an irregular hypoechoic lesion; BIRADS grade was 4 (fig. 3). Appearances were suggestive of ma-
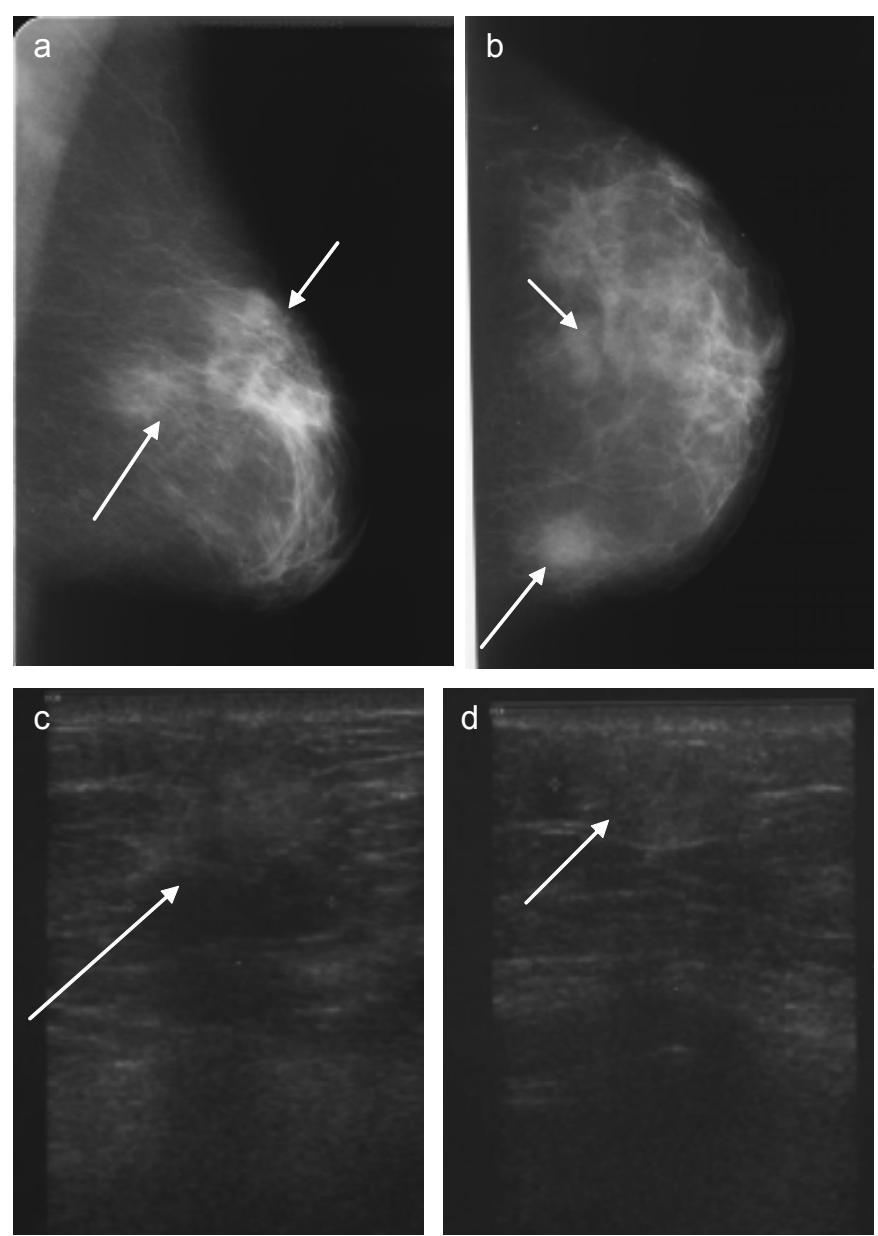

Fig. 1. Mammography of the left breast $(\mathbf{a}, \mathbf{b})$ demonstrates several illdefined $2 \mathrm{~cm}$ masses in the left upper inner quadrant (long arrow) and in the left upper central breast (short arrow). Ultrasound of the lesions (c, d) demonstrated several $2 \mathrm{~cm}$ hyperechoic mass lesions which corresponded to the mammographic abnormalities noted above.
Fig. 2. Screening mammograms of the left breast (a, b) demonstrated an unusual $2 \mathrm{~cm}$ density in the left lower inner quadrant. Ultrasound of the lesion (c) demonstrated a $2 \mathrm{~cm}$ ill-defined mass lesion.

Fig. 3. Mammography (a, b) demonstrates a $5 \mathrm{~cm}$ mass lesion in the left retroareolar area (white arrow). Ultasound of the lesion (c) confims a $5.2 \mathrm{~cm}$ complex hypoechoic mass lesion.
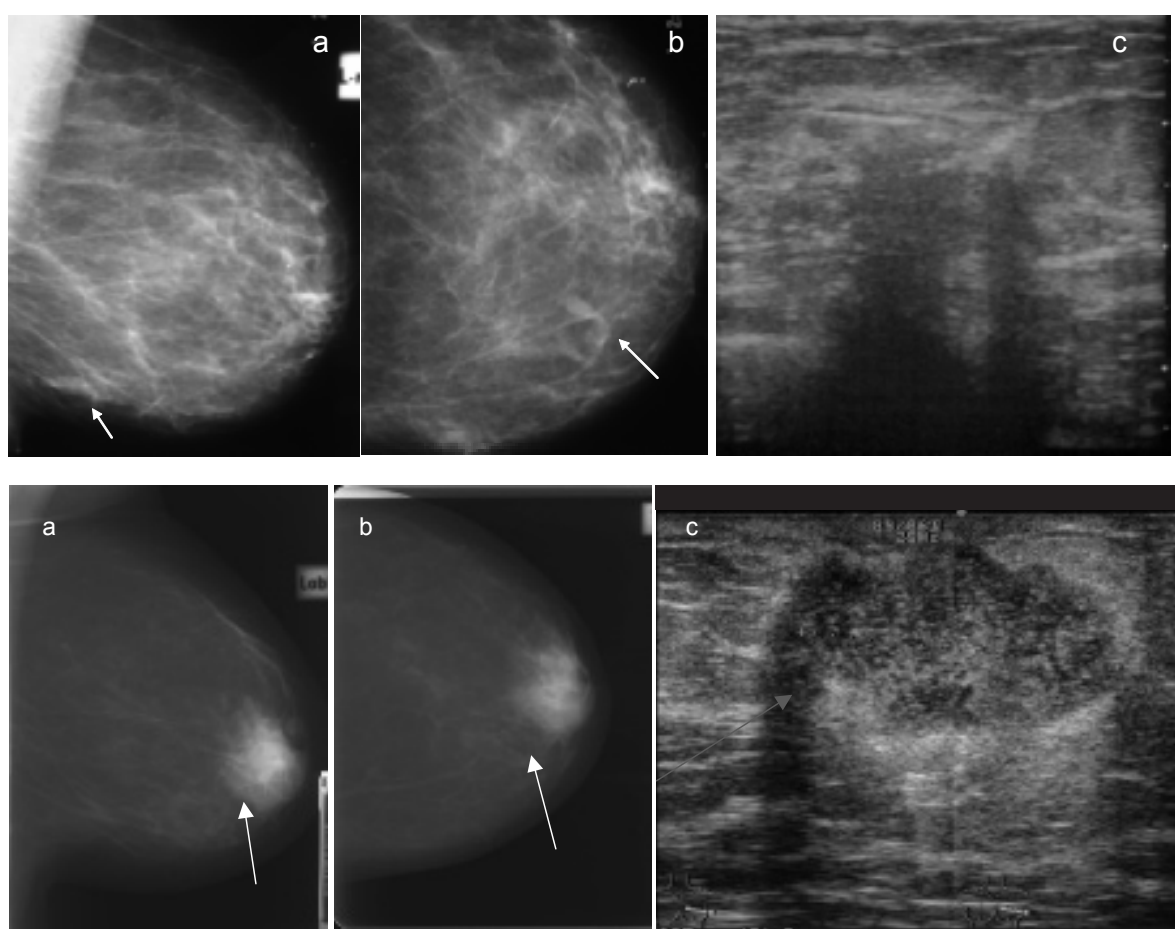
lignancy, but given the patient's history, recurrent abscess formation was also a possibility. As no fluid could be aspirated from the lesion, a core biopsy was performed. This showed chronic granulomatous inflammatory cells (B2) and was histologically labelled as granulomatous mastitis. Due to the disparity between the radiological assessment and the pathological findings, an excision biopsy of the lesion was carried out, which showed duct ectasia with an inflammatory sinus and periductal granulomatous inflammation with fat necrosis. In retrospect, the underlying diagnosis was almost certainly that of duct ectasia with recurrent infection and inflammatory reaction rather than an idiopathic granulomatous mastitis.

\section{Discussion}

Granulomatous mastitis is a rare non-neoplastic disease of uncertain aetiology. The incidence of this condition is also uncertain. Until 1999, there were only 120 cases described in the world literature [2]. It is reported to occur predominantly in women of childbearing age and is generally unilateral. In one relatively large series of 25 patients published recently, the mean age at presentation was 36.5 years [3]. Correlations between idiopathic granulomatous mastitis and breastfeeding, smoking, and use of the oral contraceptive pill have all been postulated but never proven.

The most common presentation is that of unilateral breast mass $(57 \%$ in one series of 21 cases) or breast pain $(33 \%)$. Nipple inversion, axillary lymphadenopathy, and fistula formation were all less common symptomatic presentations [4]. Radiological features of granulomatous mastitis are non-specific. The most common mammographic findings are of an asymmetric density or an ill-defined mass, but findings of multiple small ill-defined masses have also been described [5-8]. Ultrasound findings are also variable, a feature demonstrated in our patients. The most common appearance is that of a discrete but irregular hypoechoic mass lesion; however, multiple hypoechoic masses, parenchymal heterogeneity, and area of mixed echogenicity with parenchymal deformity have all been described [5-8]. The few studies using dynamic enhanced magnetic resonance imaging (MRI) to evaluate granulomatous mastitis have also revealed a variety of radiological appearances and enhancement patterns including ring-like areas of enhancement in some patients; areas of nodular enhancement; and heterogeneously enhancing areas without mass effect [6].

While the aetiology of true idiopathic granulomatous mastitis is unclear, granulomatous disease within the breast may also be secondary and represent a manifestation of a systemic disease such as Wegener's granulomatosis [9], sarcoidosis, diabetes mellitus, or the connective tissue disorders. Little, however, has been written about this topic [10]. The clinical findings of granulomatous mastitis often mimic malignancy, a feature demonstrated in a number of case series and reports [2-8, 10-11].

A number of rather large series of cases of granulomatous mastitis have been reported from the developing world, particularly within the last 8 years $[3,4,6,8,10$.] This is unusual for what had hitherto been a rare disease. Indeed, some au- thors have postulated that some of these cases may be a reflection of the underdiagnosis of tuberculous mastitis [11]. The cytomorphic pattern seen in tuberculous mastitis is very similar to that seen in idiopathic granulomatous mastitis. Equally, as it may not always be possible to detect acid-fast bacilli in histological sections of idiopathic granulomatous mastitis, an accurate diagnosis can only be made when clinical information is taken into account [4]. Also, in some circumstances, it may prove difficult for pathologists to differentiate between true idiopathic granulomatous mastitis and periductal mastitis, particularly if the surgical excision is incomplete or there has been a previous surgical procedure [12]. This proved to be the case with one of our patients (Case 3 above), where the misdiagnosis was made based on a core biopsy result and excision biopsy confirmed the correct diagnosis.

Polymerase chain reaction (PCR) for mycobacterium tuberculosis DNA can also be performed to confirm the diagnosis if stains for microorganisms are negative. One study from 2004 retrospectively reviewed the diagnoses in 26 patients labelled as having idiopathic granulomatous mastitis. Clinically, 4 cases $(15 \%)$ were associated with duct ectasia, 8 (31\%) with abscess, and there was no such association in 14 cases (54\%). Of the 19 cases with PCR for tuberculosis, 1 case showed $M$. tuberculosis DNA in the sample, raising the possibility of occult tuberculosis infection. Special stains and cultures for microorganisms in these 19 cases had all been negative [13].

The management of the patients with idiopathic granulomatous mastitis generally consists of wide local excision $[4,8$. $]$ Recurrences, fistula formation, and secondary infection are well-documented complications [2-8, 10-11]. Corticosteroid treatment also has its advocates and has been reported as decreasing the lesion size and improving wound healing [8]. The salient point with regard to treatment appears to be obtaining a correct diagnosis, as it would be completely inappropriate to treat a patient with active infection with corticosteroids, or to deprive a patient with active tuberculosis of anti-tuberculous medication. Some patients with secondary granulomatous disease, such as our cases 1 and 2, may need no specific local treatment at all; simple reassurance and treatment of their underlying medical condition may be all that is required.

In conclusion, granulomatous mastitis is a rare inflammatory condition of the breast, which may clinically mimic malignancy and may be misdiagnosed as carcinoma. There are, however, other causes of similar histological appearances within the breast. We report, in this series, 3 examples of this, including the first screen-detected case of granulomatous breast disease. Clearly, effective feedback in the context of a multi-disciplinary team is vital in these challenging cases where the patient's history, as is so often the case in medicine, provides the key to the correct diagnosis.

\section{Conflicts of Interest}

The authors declare that they have no conflicts of interests. 


\section{References}

1 Kessler E, Wooloch Y: Glaucomatous mastitis: a lesion clinically simulating carcinoma. Am J Clin Path 1972;58:642-646.

2 Ayeva-Derman M, Perrotin F, Lefrancq T, et al.: (Idiopathic glaucomatous mastitis. Review of the literature illustrated by 4 cases). J Gynecol Obstet Biol Reprod (Paris) 1999;28:800-807.

$\checkmark 3$ Azlina AF, Ariza Z, Arni T, Hisham AN: Chronic glaucomatous mastitis: diagnostic and therapeutic considerations. World J Surg 2003;27:515-518.

4 Akcan A, Akyndiz H, Deneme M, et al.: Granulomatous lobular mastitis: a complex diagnostic and therapeutic problem. World J Surg 2006;30:1403-1409.

5 Heer R, Shrimanker J, Griffith CDM: Granulomatous mastitis can mimic breast cancer on clinical, radiological and cytological examination: a cautionary tale. Breast 2003;12:283-286.

6 Ozturk M, Mavili E, Kahriman G, et al.: Granulomatous mastitis: radiological findings. Acta Radiologica 2007;48:150-155.

7 Memis A, Bilgen I, Ustun EE, et al.: Granulomatous mastitis: imaging findings with histopathologic correlation. Clin Radiol 2002;57:1001-1006.

$>8$ Asoglu, O, Ozmen V, Karanlik H, et al.: Feasibility of surgical management in patients with granulomatous mastitis. Breast J 2005;11:108-114.

9 Veerysami M, Freeth M, Carmichael AM, et al.: Wegener's granulomatosis of the breast. Breast J 2006;12:268-270.

10 Bakaris G, Yuksel M, Ciragil P, et al.: Granulomatous mastitis including breast tuberculosis and idiopathic lobular granulomatous mastitis. Can J Surg 2006;49:427-430.

11 Bani-Hani KE, Yaghan RJ, Matalka II, et al.: Idiopathic granulomatous mastitis: time to avoid unnecessary mastectomies. J Breast 2004;10:318-322.

12 Lester SC: Differential diagnosis of granulomatous mastitis. Breast J 2005;11:534 535.

13 Tse GM, Poon CS, Ramachandram K, Ma TK, Pang LM, Law BK, Chu WC, Tang AP, Cheung HS: Granulomatous mastitis: a clinicopathological review of 26 cases. Pathology 2004;36:254-257. 